\title{
COM \\ A survey and evaluation of mobile apps in science centers and museums
}

\section{Maycon Gomes Barbosa, Luiz Antonio de Saboya and Diego Vaz Bevilaqua}

\begin{abstract}
This paper studies how science centers and museums around the world have used mobile apps with museum guide characteristics and tries to identify the best interface design principles to improve their use as a tool for interaction with the public. For this purpose, we mapped mobile apps from science centers and museums and applied an evaluation tool for each one to identify good practices. This allowed us to produce guidelines for identifying good practices in the development of apps as a way of expanding visitors' experience in these institutions through these devices.
\end{abstract}

Keywords

DOI

Introduction
Science and media; Science centres and museums; Visual communication

https://doi.org/10.22323/2.20050201

Submitted: 18th January 2021

Accepted: 11th June 2021

Published: 9th August 2021
New technologies incorporate innovations in society, making our lives more practical and even more pleasurable. However, on many occasions, we do not even notice the apps' presence in our daily routine, and many of them thus end up becoming ubiquitous. We expect them to be present with their benefits whenever possible, even in leisure moments. For example, Disney has a mobile app called Disney World, in which visitors can access information on the expected waiting time for each attraction in the park, viewed directly on the park map, in addition to other pertinent features such as information on schedules and ticket purchase. A park does not have to be as big as Disney to reap the benefits of engaging visitors with new technology like smartphone mobile apps.

Science museums and centers seek to keep up to date with the available technological developments in today's society. New technologies have the potential to renew the experience a visitor can have with a museum, expanding this experience. A better experience can alter the way visitors perceive the museum's exhibits, bringing benefits for both the museum and visitors. 
Among the new technologies that have emerged in recent years, mobile applications, or apps, ${ }^{1}$ have an ever-growing presence in various sectors of society. As with other sectors, science museums and centers worldwide have taken advantage of this technology to improve communication with visitors and allow new interactions. Mobile apps are dynamic, allowing a series of interactions with users that are not always available on personal computers, since they are executed on compact physical devices like smartphones and tablets, which are highly versatile and portable.

During the COVID-19 pandemic, some 95\% of the world's museum institutions [International Council of Museums, 2020b] have had to close their doors to the public as a health measure to prevent SARS-CoV-2 transmission. The principal forms of indoor contagion in museums involve airborne transmission between visitors and staff, who may be in close contact inside the institutions' galleries, generally closed places, and through the interactive tactile exhibits and devices, which require constant handling by the public. Measures to prevent SARS-COV-2 transmission inside museums have thus included recommendations such as constant sanitation of the touchable devices and, in some cases, their deactivation [International Council of Museums, 2020a].

Given this scenario, mobile apps can play an important role in the decision to open or reopen museums [Cuseum, 2020; Spencer, 2020]. Since smartphones are used individually and are not shared by the public, they are appropriate devices for the prevention of COVID-19 transmission. Audioguides can be transmitted by wi-fi directly to the visitor's smartphone, QRCodes can be used to enable devices, and digital maps can help the user to navigate the museum's spaces, all solutions that make the visit safer.

Since mobile apps are a recent technology, we still cannot precisely calculate the impact of their use on a large scale. However, their reach is growing every day and the use of this tool in education has multiplied exponentially in recent years. As reported in Hirsh-Pasek et al. [2015], in January 2015 the number of apps classified as educational and available in Apple Store alone exceeded 80,000 software packages. Those authors affirm that mobile apps can enhance learning if they can provide an active learning environment that goes beyond swipe and tabs, that engages the learner in its process, and that is meaningful and socially interactive, so those pillars should be considered in its design principles [Hirsh-Pasek et al., 2015].

In a systematic literature review about digital technology for enhancing the museum visitor experience, Shah and Ghazali [2018, p. 40] identified that "smartphones and tablets are the two top types of technology, which had been used, because most visitors bring their own devices when visiting the museums". Among the articles collected for the study, $46 \%$ of them were related to mobile technologies, which have been used with various types of application to enhance visitors' experience, such as virtual reality, augmented reality, QR code, eye tracking and 3D display [Shah and Ghazali, 2018].

Almeida de Souza [2018] discusses the effect of museums' use of mobile apps. She claims that they provide flexibility in the way visitors can grasp the content,

\footnotetext{
${ }^{1}$ Mobile apps are software packages developed to be installed in mobile electronic devices such as smartphones.
} 
respecting their limitations and cognitive capacities, thereby allowing the democratization of the exhibit space. One of the resources allowed by mobile apps is the capacity for personalization. Individuals can experience the exhibit according to their wishes and curiosities. However, it is important to be aware of some possible limitations in the smartphone's operational resources, such as battery life and internet data package [Almeida de Souza, 2018]. The author also recommends some precautions with the use of new technologies, to avoid interfering in the visitor's engagement with the exhibit's information, in case the visitor becomes more attracted to the app itself than to the actual museum [Almeida de Souza, 2018].

Focusing on controlling, insofar as possible, any mismatch between the visitors' focus on the exhibit and their distraction with the mobile app, one of the guidelines comes from the study by Kruk [2015]. The author points out that there is a balance between the app that serves as a supplement and the museum's physical space.

One should be aware of the fact that mobile devices may not bring great advantages when compared to traditional or conventional media, especially when the application is not well designed. A study by Lanir et al. [2020] expresses some findings in this direction. The authors mention the comparison they made regarding three types of supporting media to convey information on a history museum. They were guides for use by students in a visit to a museum: one a constructivist printed booklet, the second an informative mobile application, and the third a constructivist mobile application. All the items contained the same information, and the authors concluded that:

\begin{abstract}
While the constructivist mobile application showed overall better performance over the paper guide, we did notice several advantages when using the paper booklet (...). Looking at the design of the mobile applications, a tablet screen is often too small for presenting all the required information (...).

Furthermore, the digital application does not afford natural navigation between screens (...). Conversely, the paper guide affords students' easy examination of materials located in different pages for their processing. [Lanir et al., 2020, p. 4]
\end{abstract}

The interactive science center Exploratorium, in San Francisco, has been discussing the use of wireless and mobile technologies since 1998. The Electronic Guidebook Project aimed to use mobile devices to enhance visitors' experience in exploring, requesting information, explaining, and recommending [Hsi, 2002]. Most users reported that "handheld resources motivated and prompted new ways to play with the exhibit as well as prompted them to think further about many ideas inspired by the mobile web content" [Hsi, 2002, p. 52]. In a conference in 2001, [Exploratorium, 2001] the potential of mobile devices to improve visitors' experience in a museum setting was characterized in the following ways: allowing a customized experience; diversifying sources of content; accessibility; expanding the role of a visitor, as a curator, researcher, or content provider; stimulating further exploration and discoveries in the exhibition; enabling a personal expanded meaning experience; enabling experiences that go beyond the walls of the museum; catalyzing social interactions; extending the visitors' observational capabilities; increasing interactivity with exhibits. Regarding the user interface, the summary report of the conference also identifies the need for a design that is easy 
to use and does not interfere with the physical experience. In 2018, Exploratorium held another conference on the subject, called Conference on Mobile Position Awareness Systems and Solutions (COMPASS). One of the key speakers, Rogers [2018, p. 29] summarized what she feels are essential design principles for mobile apps in museums. They should design to enhance rather than oversteer; design to engage rather than simply guide to a place; design to enchant; encourage curiosity rather than content consumption; combine playfulness with local interest; design for memorable experiences.

According to Green [2017], the current use of mobile apps in science museums and centers is practically limited to the migration of the museum's guide or exhibit folder to the cellphone screen, with little or no relevant new experience between the public and the museum. In such situations, we often see the introduction of new technology in the social setting. There can always be a tendency to mimic or transpose the previous forms onto the new vehicle or technological medium. Not surprisingly, most initiatives with the use of mobile apps in these institutions display this bias.

Many science museums and centers already have guidelines on the use of mobile app technology as a way of popularizing their collections. A search yielded the example of the Explorer, the mobile app of the American Museum of Natural History (AMNH) in New York City, which allows users to personalize their experience, to experience augmented reality with the Avatour, to test their knowledge, and to purchase tickets while avoiding lines, among other features. Other examples include the NHM Visitor, the app of the Natural History Museum in London, which teaches users how to reach the museum, to know in real-time where they are located inside the museum, and to purchase tickets, among other features. The California Academy of Sciences Visitor Guide, the app of the California Academy of Sciences, is 100\% offline a mobile guide based on previous visitors' advice and experience. Finally, we have the example of the app for the Rio de Janeiro Botanical Garden, featuring direct interactivity with the Botanical Garden's map, guiding visitors more precisely around the grounds.

The current study investigated how science museums and centers associated with two renowned groups that convene museums from around the world, with the greatest focus on the United States, Canada, Latin America, and the Caribbean, have adopted mobile apps as a tool for interaction with the public. The study featured a state-of-the-art survey and an evaluation matrix to identify the potentialities and qualities of the interface solutions. Finally, we used this evaluation to develop guidelines and recommendations for developing apps with these characteristics.

Mobile interface design
Norman [2002] exemplifies bad designs in a series of simple everyday objects to which we can relate. On several occasions we have difficulty in performing their functions, such as opening a door, turning on switches, opening the water in a spout, handling a slide projector, among others. The design must help the user, avoiding any kind of frustration. Preece, Rogers and Sharp [2002] understand interaction design as projecting interactive products to support the way people communicate and interact in their daily lives, whether at home or work. 
Interaction design is an umbrella term, encompassing practices of graphic design, product design, industrial design, the film industry, and visual arts, which are used to study, analyze and design based on user experience [Preece, Rogers and Sharp, 2002]. It aims to improve and expand users' experiences, studying, analyzing, and seeking to understand which desirable and undesirable aspects they may have or avoid. Interaction design studies exactly how to improve the interaction between people and objects with any level of interactivity, both physical and digital, being an area that uses the science of cognition as one of the foundations to generate better solutions in design [Norman, 2002].

Mobile interface design is the way the smartphone or tablet screen with which the user interacts is designed to achieve the objective satisfactorily, where the experience is mediated and enhanced by tests with potential users of the interface [Kruk, 2015]. From the designer's point of view, an app should not be designed only for the content but should mainly consider the interface that will be used by the user and the functionalities the app will present. The interface defines how the dynamics of the interaction with the app plays out, and depending directly on the interface, the app may be intuitive, inviting, or effective. In this context, when we use new information technologies, we should not lose sight of the interaction design perspective, capable of enabling the necessary solutions to expand the user's experience.

With a focus on smartphone users, studying them in greater depth allows user-centered design solutions that assist museum visitation without diverting attention from the exhibit's information to be fostered. Almeida de Souza [2018] and Kruk [2015] note that the interaction's design in mobile apps or other technological resources is one of the crucial points that can greatly enhance the effectiveness of communication with visitors and their experience, focusing on their needs and difficulties. Almeida de Souza [2018] explains that a museum project needs to be centered on the visitor, using resources that analyze the public's interaction with the available interfaces and that consider efficiency, efficacy, and a good user experience. Still, despite this growing expansion of mobile app use, the user's experience is not always the most effective focus for successfully concluding the task the user seeks [Kruk, 2015].

Methodology

This study is a section of a larger research effort, aiming to understand how mobile apps can contribute to the mission of science museums and centers, improving and expanding the public's experience based on users' behavior, seeking to identify the best design solutions. For this purpose, the specific aim of this report in the present article is to present a ranking order of existing apps for museums and science centers, which could suggest the best practices regarding this kind of software. Interface design is a very important step to establish a good interaction with the public, and a confusing and badly designed app is a barrier to expanding visitors' experience in these institutions through these devices. Although some of the findings are ordinary in interface design for mobile apps, these institutions have some common characteristics which demand specific solutions; in our opinion, it is important to share them with a larger community.

We used two methodological tools for this purpose, which we describe next. The first aims to map the existing apps, followed by a second tool to assess and identify 
good practices. This mapping of mobile smartphone apps focused on science museums and centers has the objective of identifying the state-of-the-art and understanding how these institutions are employing this new tool. The survey focused on the iOS system, one of the most popular on the market.

Since we aimed to obtain a well-demarcated and more secure search corpus, we conducted the search for mobile apps of science museums and centers based on the institutions that are members of the Association of Science-Technology Centers [ASTC, 2021b] and the institutions present in the publication Guía de Centros y Museos de Ciencia de América Latina y el Caribe ${ }^{2}$ [2015]. According to its website, the ASTC [2021a] is a professional organization with headquarters in the United States that convenes science centers and museums, besides museums of natural history, children's museums, and other organizations dedicated to science education. Although global in nature, it has a focus on North America, specifically Canada and the United States. Meanwhile, the Guía de Centros y Museos de Ciencia de América Latina y el Caribe [2015] is a publication of the Network for Popularization of Science and Technology in Latin America and the Caribbean [RedPOP, 2021] to map these scientific and cultural spaces in Latin America and the Caribbean. The two lists thus encompass the great majority of such institutions in the Americas, besides some others from elsewhere in the world. Due to the authors' linguistic limitations, it was necessary to limit it geographically.

For a mobile app to be made available on a user's smartphone, it must be downloaded from the operating system's virtual store. However, the objective of this methodological stage would have been compromised if we had searched purely in the virtual stores using keywords such as "science museum". Searches for mobile apps in smartphone virtual stores or search websites tend to display the results according to the search mechanism's algorithm, which ends up influencing the result, depending on the conditions of the user performing the search [Valadares Cendón, 2001].

The two lists furnish names, addresses, and websites for these institutions. ASTC lists 484 members, ${ }^{3}$ and the Guía de Centros y Museos de Ciencia de América Latina y el Caribe [2015] lists 464 science museums and centers. ${ }^{4}$ The search was thus conducted in the institutions' respective websites, observing whether there was some specific place on the website that indicated the existence of a mobile app for the museum institution. If there was no specific area indicating the existence of such a mobile app, the site's own internal search mechanism was used, inserting the word "APP" to perform the search. The idea was to find the link on the site that led to the smartphone's virtual store to download the app.

Ultimately, when all the previous attempts failed to yield positive results, a search was conducted in Google with the name of the institution plus the word "iTunes". This method produced positive results in some cases. However, it must be said that having been developed by a science museum or center, the mobile app should be easy for the public to access, without the need to rely on difficult searches, which does not guarantee that the desired app will be found.

\footnotetext{
${ }^{2}$ Guidebook of Science Centers and Museums of Latin America and the Caribbean.

${ }^{3}$ Survey performed from September to November 2018.

${ }^{4}$ Survey performed from November to December 2018.
} 
This survey allowed us to assess the state-of-the-art in the development of these apps. An evaluation matrix was created for this stage [Sanoff, 1968]. This kind of matrix works by judging something's positive and negative qualities, pertaining to a given context, through criteria determined by the evaluator. The evaluation matrix functions as a "filtering" system for certain "alternative solutions" to a certain design problem.

When more than one criterion is used, they must be displayed in decreasing order starting with the most relevant, with a weighting stance from one criterion to the next.

This original method, proposed by Sanoff, was adapted regarding today's situation. What was evaluated was not alternative solutions in a design process environment, but rather existing solutions of in-use applications related to museum contexts.

This process aims to classify mobile apps with the best solutions based on the chosen criteria. Among the various aspects that an evaluation can include, our intention focused on aspects of performance, functionality, and ease of operation, and other aspects can be added.

As an evaluation matrix procedure, we created a list of criteria and a list of alternative solutions. We then organized the criteria in decreasing order, from the most important to the least important. We then scored the criteria pair-by-pair, starting with the least important, receiving a score of 1, which is its absolute value (AV). From there on, we scored the other criteria, always pair-by-pair, where the next criterion on the list we created received a certain weight in relation to the previous criterion, and this weight was multiplied by the AV of the previous criterion. This procedure continued until the most important criterion received a weight in relation to the immediately previous criterion and its AV was found, thus producing a measurement among all the criteria. Figure 1 illustrates the simulation:

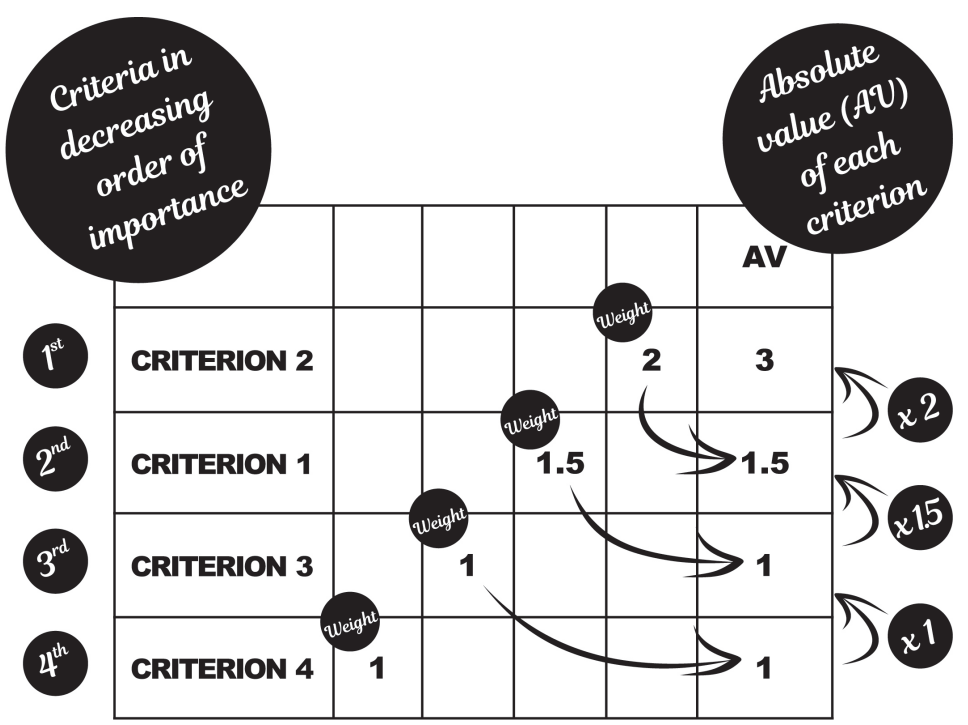

Figure 1. Measurement of each criterion's absolute value in the evaluation matrix.

Our study follows the order of the following design principles [Preece, Rogers and Sharp, 2002] as criteria: 
1. Visibility: ranking first among the criteria, since it is the necessary design principle for adequate visualization of the interface. In its absence, any other design principle would be practically impossible.

2. Affordance/Convention: ranking second among the criteria, since it is the design principle that gives users clues on how to use the interface. In the absence of the visibility design principle, it would not be seen and would not have the expected effect.

3. Feedback: third place among the criteria, since it is associated with the design principle of visibility. It is the design principle that indicates some kind of informative feedback to users, for them to perform the desired action.

4. Consistency: fourth place among the criteria, since in specific cases the inconsistency can be a better solution than those previously known by the users.

5. Constraints: fifth and last among the criteria, since it is a principle which if poorly applied can compromise the design principle of visibility (which we analyze as the most important).

Figure 2 shows the measurement of each criterion's absolute value in the evaluation matrix:

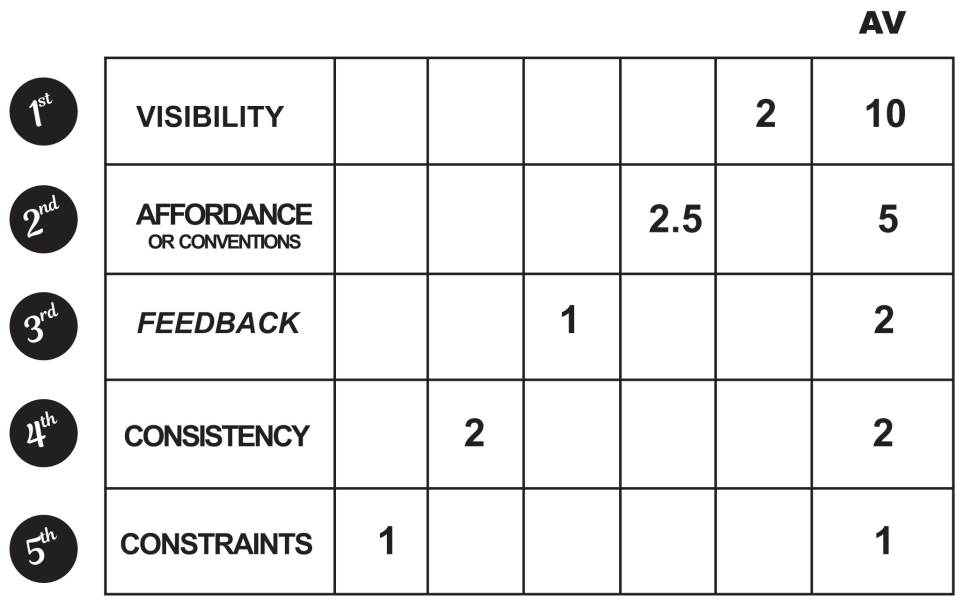

Figure 2. Measurement of the absolute value of each criterion used in the evaluation matrix in our study.

The next step was to define the scale factors in the evaluation for the alternative solutions, as exemplified in Table 1 :

Table 1. Factors in alternative solutions.

$$
\begin{aligned}
+2 & \text { Helps significantly } \\
+1 & \text { Helps a little } \\
0 & \text { Indifferent } \\
-1 & \text { Interferes a little } \\
-2 & \text { Interferes significantly }
\end{aligned}
$$

Next, we cross-analyzed the scale factors in the alternative solutions, which in our study are the mobile apps, with the absolute values for each criterion, elaborating 
the evaluation matrix. In our study, as mentioned before, an adaptation was made, so that we exceeded the basic limits of the conventional evaluation matrix, which normally assesses an item with various solutions, assessing a total of 11 items with 38 alternative solutions. The items that were evaluated are displayed in Table 2.

Table 2. Items that were evaluated in the apps with the matrix of evaluation.

\begin{tabular}{|ll|}
\hline Side list & Navigation between screens ("Back button") \\
Presentation of content & Images \\
Suggestions & Map \\
Exhibition section & Favorites section \\
Presentation of texts & Tickets section \\
Search mechanism & \\
\hline
\end{tabular}

The scores were attributed by the first author of this paper, who downloaded all mobile apps and tested them. After initial scoring, the results were validated by the other authors. In the case of disagreement in the process, the authors gathered together and discussed it until a consensus was reached. There is a great deal of subjectivity in this process, so it is possible, that even following the same steps, different researchers can find different scores. However, we tried to be as precise as possible in describing the choices we made, so they can be fully understood.

Finally, the design principles occurring as best practices for designing new mobile apps were organized from the selected literature, as well as the examples that were found while evaluating the apps from different museums. These best examples were organized to conform to a small set of design principles for mobile solutions for science centers and museums.

Results

Among all the museum institutions studied, we found 54 mobile apps, 45 of which were present only on the ASTC membership list, eight in the guide published by RedPop [Guía de Centros y Museos de Ciencia de América Latina y el Caribe, 2015], and one listed in both. Of these, we evaluated 38 mobile apps (Table 3) with characteristics of museum guides and which were possible to download from the virtual store. Of these, 33 were listed by ASTC and five by RedPOP.

Besides the mobile apps listed above, we found 16 more (Table 4), 12 of which were listed by ASTC, three by RedPOP [Guía de Centros y Museos de Ciencia de América Latina y el Caribe, 2015], and one on both lists. However, we did not evaluate these apps in the current study, due to the following difficulties: the virtual store did not provide access to the mobile app's home country; the mobile app was outdated and the virtual store blocked downloading it; the mobile app used a language in which the study's authors were not fluent; there was some type of error or failure that prevented the mobile app's full functioning; interaction was via audio-only; interaction was with a geographic territory outside the museum's physical space.

As we proceeded with our methodological sequence, we applied the evaluation matrix to the apps listed in Table 3, referring to the following items: side list, presentation of content, suggestions, exhibition section, presentation of texts, search mechanism, navigation between screens ("back button"), images, maps, 
Table 3. Mobile apps evaluated.

\begin{tabular}{|c|c|}
\hline \multicolumn{2}{|l|}{ ASTC } \\
\hline Institution & Mobile app \\
\hline American Museum of Natural History & Explorer \\
\hline Ann Arbor Hands-On Museum & AAHOM \\
\hline Children's Discovery Museum of San José & $\mathrm{CDM}$ \\
\hline Children's Museum of Houston & CMH More \\
\hline Cranbrook Institute of Science & Cranbrook \\
\hline Fernbank Science Center & Fernbank \\
\hline Gwacheon National Science Museum & Exhibition \\
\hline Haus der Musik & HdM Guide \\
\hline Hong Kong Science Museum & iM Guide \\
\hline International Museum of Surgical Science & IMSS \\
\hline Long Island Children's Museum & LICM4all \\
\hline Milton J. Rubenstein Museum of Science \& Technology (MOST) & The MOST \\
\hline Milwaukee Public Museum & mpm all in \\
\hline MOSI (Museum of Science \& Industry) & MOSI Tampa \\
\hline MOXI The Wolf Museum of Exploration + Innovation & Access MOXI \\
\hline Museum of Discovery and Science & MODS \\
\hline Natural History Museum of Utah & NHMUTrialhead \\
\hline North Carolina Museum of Natural Sciences & NC NatSci \\
\hline North Museum of Nature and Science & NCMNS \\
\hline Omaha Children's Museum & OmahaChildren'sMuseum \\
\hline Peggy Notebaert Nature Museum & NatureMuseum \\
\hline Peoria Riverfront Museum & PRM \\
\hline Phillip and Patricia Frost Museum of Science & Frost Science \\
\hline Putnam Museum and Science Center & Putman \\
\hline Science Museum Group & Science Museum \\
\hline Science Museum of Virginia & The Muse \\
\hline Shenandoah Valley Discovery Museum & Discoverer \\
\hline $\begin{array}{l}\text { South Florida Museum, Parker Manatee Aquarium and Bishop } \\
\text { Planetarium }\end{array}$ & Pathways \\
\hline The Children's Museum of Indianapolis & Children'sMuseumIndianapolis \\
\hline The Franklin Institute & Franklin Inst. \\
\hline The Mind Museum & TMM \\
\hline The Springs Preserve & LV Springs \\
\hline Witte Museum & New Witte \\
\hline \multicolumn{2}{|l|}{ RedPOP } \\
\hline Institution & Mobile app \\
\hline Instituto Inhotim & Inhotim \\
\hline Instituto de Pesquisas Jardim Botânico do Rio de Janeiro & Jd.BotânicoRJ \\
\hline Museu de Microbiologia & InstitutoButantan \\
\hline Parque Explora & AcuarioExplora \\
\hline Museo Militar de El Salvador & MuseoMilitar \\
\hline
\end{tabular}

favorites section, and tickets section (it is important to notice that those items belong to each application, and this is a step further in sophistication in our evaluation matrix, which goes beyond the traditional matrix). These items were submitted to the criteria of visibility, affordance/convention, feedback, consistency, 
Table 4. Mobile apps not evaluated in the current study.

\begin{tabular}{|c|c|}
\hline \multicolumn{2}{|l|}{ ASTC } \\
\hline Institution & Mobile app \\
\hline Computer History Museum & CHM Tour \\
\hline COSI & COSI Science \\
\hline Denver Museum of Nature \& Science & DMNS eCARD \\
\hline Greensboro Science Center & Greensboro Science Center \\
\hline Harvard Museums of Science \& Culture & Harvard Times Trials \\
\hline Huntington Museum of Art & Huntington Museum Audio Guide \\
\hline Independence Seaport Museum & Independence Seaport Museum \\
\hline Kayseri Science Center & Akıllı Şehir Kayseri \\
\hline Kern County Museum & Kern County Museum \\
\hline $\begin{array}{l}\text { National Museum of Emerging Science and } \\
\text { Innovation (Miraikan) }\end{array}$ & Miraikab Notebook \\
\hline National Taiwan Science Education Center & iGuidePlus \\
\hline $\begin{array}{l}\text { QUESTACON, Australia's National Science and } \\
\text { Technology Centre }\end{array}$ & Questacon Walks of Wonder \\
\hline \multicolumn{2}{|l|}{ RedPOP } \\
\hline Institution & Mobile app \\
\hline Museu das Minas e do Metal & Media Guide Mmm \\
\hline Oi Futuro & Oi_Futuro \\
\hline Aquário de Ubatuba & Tour Virtual \\
\hline \multicolumn{2}{|l|}{ Both } \\
\hline Institution & Mobile app \\
\hline Centro de Ciencias y Artes AC (Planetario Alfa) & Planetario Alfa \\
\hline
\end{tabular}

and constraints (design principles), where the measurement was executed for each of the 38 mobile apps, that is, our alternative solutions.

The evaluation matrix was applied to 38 mobile apps, with the results shown in Table 5:

Table 5. Results of the evaluation matrix applied to the apps listed in Table 3, ordered from the highest to the lowest score.

\begin{tabular}{|l|c|}
\hline Name of mobile app & $\begin{array}{c}\text { Score from } \\
\text { evaluation matrix }\end{array}$ \\
\hline Franklin Inst. & 301 \\
\hline Children'sMuseumIndianapolis & 266 \\
\hline Pathways & 234 \\
\hline Explorer & 231 \\
\hline Frost Science & 194 \\
\hline Jd.BotânicoRJ & 189 \\
\hline Inhotim & 177 \\
\hline Science Museum & 158 \\
\hline Discoverer & 145 \\
\hline NCMNS & 133 \\
\hline LV Springs & 112 \\
\hline \multicolumn{2}{|c|}{ Continued on the next page. } \\
\hline
\end{tabular}


Table 5. Continued from the previous page.

\begin{tabular}{|l|c|}
\hline Name of mobile app & $\begin{array}{c}\text { Score from } \\
\text { evaluation matrix }\end{array}$ \\
\hline iM Guide & 96 \\
\hline Smart Exhibition Guide App & 95 \\
\hline The MOST & 84 \\
\hline AcuarioExplora & 53 \\
\hline Access MOXI & 50 \\
\hline Putman & 47 \\
\hline LICM4all & 40 \\
\hline mpm all in & 40 \\
\hline OmahaChildren'sMuseum & 36 \\
\hline TMM & 36 \\
\hline PRM & 30 \\
\hline HdM Guide & 27 \\
\hline NC NatSci & 27 \\
\hline The Muse & 27 \\
\hline Cranbrook & 23 \\
\hline MODS & 21 \\
\hline MuseoMilitar & 18 \\
\hline New Witte & -27 \\
\hline CDM & -40 \\
\hline NHMUTrialhead & -40 \\
\hline MOSI Tampa & -63 \\
\hline NatureMuseum & -81 \\
\hline InstitutoButantan & -115 \\
\hline CMH More & -196 \\
\hline Fernbank & \\
\hline IMSS & -20 \\
\hline AAHOM & 30 \\
\hline
\end{tabular}

The apps with the highest overall scores were: Franklin Inst., with 301 points; Children's Museum Indianapolis, with 266 points; Pathways, with 234 points; and Explorer, with 231 points. Eight other apps also displayed relatively high performances in this methodological stage. The highest possible score on a single item was 40 points, which is the sum of all the values for the target criterion. The following mobile apps reached scores of 40 on at least one single criterion:

- The Explorer app, which ranked fourth in our overall classification and obtained the top score on the side list item;

- The MOST app, with an overall score of 84 points, obtained the maximum score on the map item;

- The Frost Science app, with an overall score of 194 points, obtained the top score on the side list item; 
- The Muse app, with an overall score of 27 points, obtained the top score on the side list item;

- The Pathways app, which ranked third overall, obtained the top score on the highlights of visitation item;

- The Franklin Inst. app not only ranked first overall but also obtained the top score on the side list item;

- The Mind Museum app, with an overall score of 36 points, obtained the top score on the side list item;

- The Inhotim app, with an overall score of 177 points, obtained the top score on the map item;

- The Jd. Botânico RJ app, with an overall score of 189 points, obtained the top score on the map item.

The current study employed a mixed methodology that showed how science museums and centers belonging to the ASTC or listed in the publication of the Guía de Centros y Museos de Ciencia de América Latina y el Caribe [2015], produced by RedPOP, have adopted and developed mobile apps for smartphones. In all, we found 54 mobile apps with the characteristics of museum guides, 38 of which functioned normally, and 16 of which presented various problems in their functioning or could not be evaluated for reasons discussed above in this article. Based on the analyses of these 38 mobile apps, we identified the key features that help users enjoy a positive experience with a mobile app in a science center or museum.

Importantly, the mobile app should present a user-friendly and objective side list, preferably displaying all the options contained in it on the same screen, without extending beyond the visible area of the smartphone's screen and thus ensuring that the options are not hidden from view. The side list generally functions as a set that groups the mobile app's main objectives, where users can easily find what they want. Some apps employ other display modes, different from lists, such as displaying options in modules and spotlighting the illustrative icons. This does not prevent them from being included in the current classification, since what matters is that the options are all displayed on the screen, regardless of their display mode, as shown in Figure 3.

Next, another salient point was the museum's map section in the mobile apps. It is important for users to be able to make selections according to their interests - such as exhibits, attractions, settings, etc. - and that these choices be highlighted on the map, and for the options on the museum's various floors (in the case of multistory museum buildings) to be as visible as possible. The app The MOST adopts a good design solution for museums in multistory buildings, visibly displaying the museum's various floors and the attractions visitors can find on them. Meanwhile, the apps from the Inhotim Institute and the Rio de Janeiro Botanical Gardens (Jd. Botânico RJ) feature good design solutions for open-air museums, with the various options displayed directly on their geographic maps, as shown in Figure 4.

Continuing with this methodological stage, a final key point that stood out from the others was the suggestions feature. Users need to continue their visits based on 

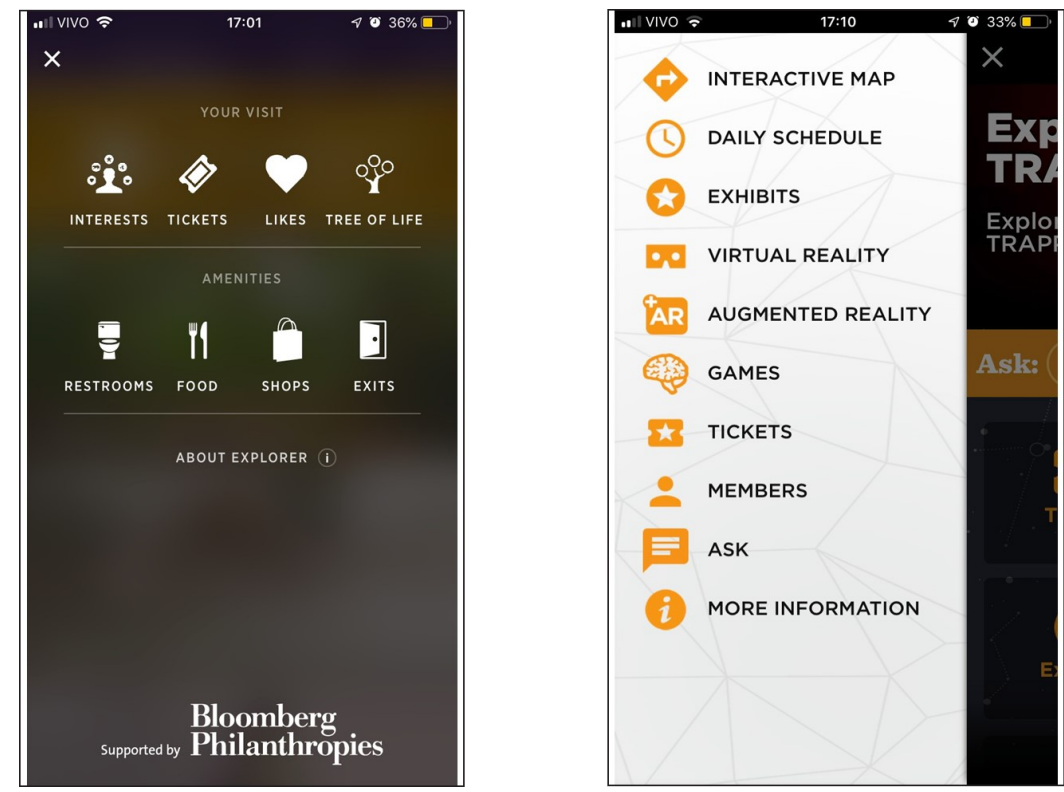

Figure 3. Screenshots from the mobile apps Explorer (right) and Franklin Inst. (left), showing the example of each app's graphic interface side lists.

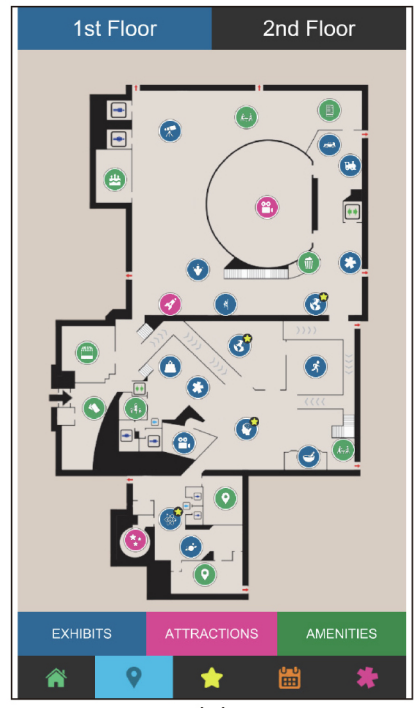

(a)

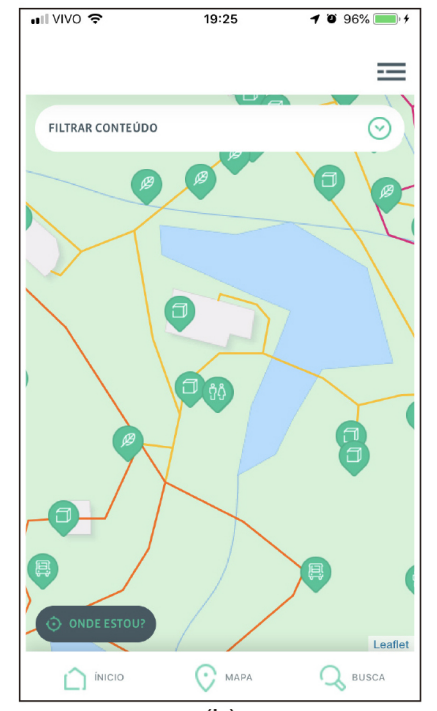

(b)

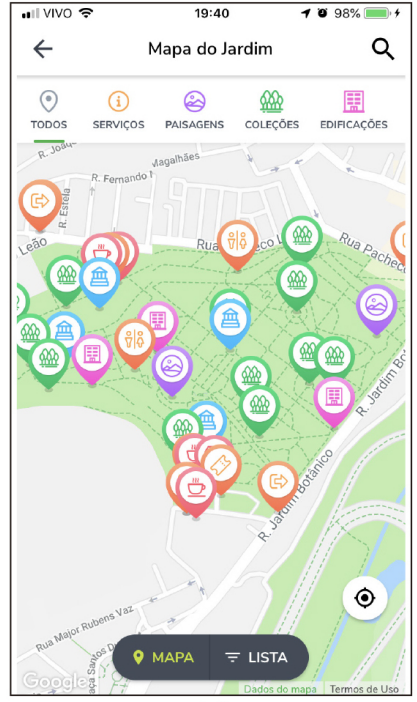

(c)

Figure 4. Screenshots from the mobile apps The MOST (a), Inhotim (b) and Jardim Botânico do Rio de Janeiro (c), showing examples of Map graphical interface.

suggestions that resonate with them. Besides, since our study focuses on the kind of app that follows an algorithm, these suggestions can point to personalized content for the respective users, guiding them to places in the museum that are more consistent with their interests, behaviors, and tastes, thus further enhancing their experience with the museum. This customization feature is frequent cited as a great potential for mobile apps in the literature [Exploratorium, 2001; Hsi, 2002; Hirsh-Pasek et al., 2015].

The mobile app Pathways presented this feature, in keeping with the design principles assessed in this methodological stage, pertaining mainly to the feedback 


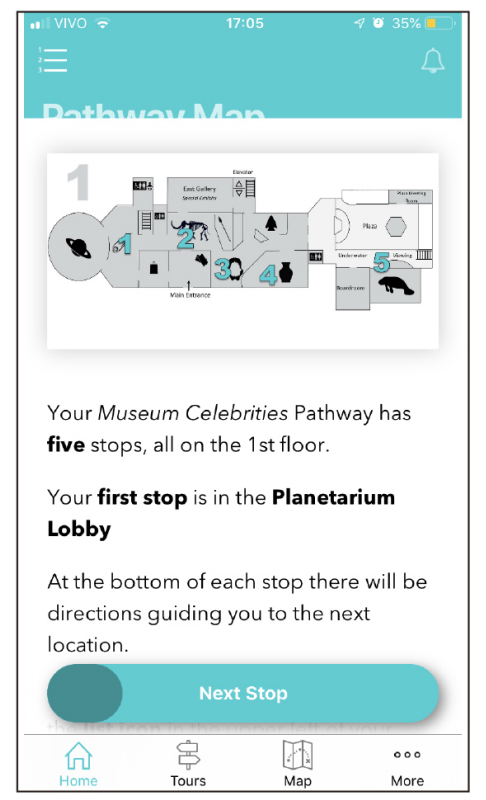

(a)

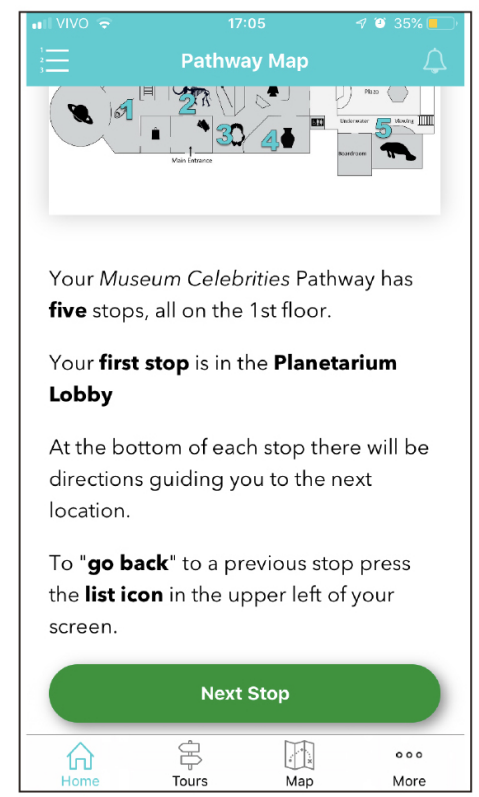

(b)

Figure 5. Screenshots from the mobile apps Pathways showing examples of graphical interface with feedback. The bottom bar changes from turquoise blue to green as we finish the content.

principle, as indicated in Figure 5. The app offers a very simple mechanism that is also quite precise in guiding users on the route or tour they choose for themselves: a turquoise blue key, identified as "Next Stop", is also a bar that changes gradually to dark turquoise blue as users peruse the content in their setting on the smartphone, indicating the amount of content in the section the user has observed in the app. When the key has completed the color shift to green, the app tells the user that they have completed the observation of the respective section and that they can switch to another section. Still, the fact that the bar changes color at the end of the process does not prevent users from switching to the next section whenever they wish, so it is not a restrictive interaction.

We note that interactive items do not need to present all the design principles [Preece, Rogers and Sharp, 2002]. Rather, they should be used wisely to orient the user's interaction as intuitively as possible.

Finally, beyond the above-mentioned items, but also concerning this methodological stage, we also suggest the following guidelines for designing a good mobile app for science museums and centers:

- Focus attention on defining how the mobile app's content is displayed, as in the example of the Explorer, an app in which the images, texts, and tickets section are organized clearly and harmoniously.

- There should be a specific section for the exhibits, organizing this content by sector, as in the Franklin Inst. App, which provided this section's use on the app's homepage and the side list, in "Exhibits".

- Focus attention on the text's graphic display, as in the Explorer app, which uses short texts to inform users about the area of the visited exhibit. 
- Design an internal search mechanism, as in the Explorer app, which highlights suggestions, facilitating the user's performance in pressing situations such as having to use the restroom, or having a snack at the snack bar.

- Design the procedures for users to return to previous screens in relation to the one they are currently on.

- Use high-quality images in terms of both aesthetics and resolution.

- Design the procedures for users to tag the contents they have enjoyed the most, creating a kind of visitor's gallery, allowing them to customize the mobile app, as in the Science Museum app, which allows users to tag the item in the exhibit they have enjoyed with the little heart symbol, which remains accessible in the favorites section.

- There should be a specific section for ticket purchases.

Besides, referring specifically to museum apps, Kruk [2015] signals that the mobile app is a tool to complement the exhibit and should be conceived in a way that is balanced with the exhibit and physical space.

This study provided the opportunity to learn how science museums and centers belonging to the ASTC or listed in the RedPOP publication Guía de Centros y Museos de Ciencia de América Latina y el Caribe have adopted mobile apps for smartphones as a strategy to help fulfill their mission. Among the more than 900 museum institutions, specifically 484 from the ASTC membership list and 464 from the RedPOP publication, only 38 institutions had fully functional mobile apps for smartphones, that is, approximately $4 \%$ of all the institutions. This shows that science museums and centers' uptake of this new technology is still relatively limited, although it has grown consistently in society.

However, it is important to highlight the good examples, such as those cited above. The Franklin Institute and the American Museum of Natural History point in new directions. As discussed, mobile apps tend to become increasingly important tools in the demand for science communication and access to information. The software technologies developed for mobile telephony have proven capable of impacting a growing number of users, based on ease of use. In parallel, as observed in various areas of electronics, informatics, and telematics, the costs involved tend to decrease steadily and the installed capacity gradually increases. The potential for growth in the use of these technological tools in the context of science museums and centers is thus likely to be high, although there are some obstacles.

At any rate, one cannot overlook the high costs these technologies still entail, particularly in developing countries. Over the course of the study, in contact with institutions in Latin America, we learned a little about the current context in these institutions, which have designed and launched their mobile apps, and where budget problems with maintenance have forced the museums to suspend the apps. We thus realize that budget shortages affect the effective continuation of mobile apps in museum institutions, especially in smaller museums. 
However, it is encouraging that we identified a positive trend that opposes the mere migration of print content from the museum guide that we know so well to the smartphone screen, as identified by Green [2017]. Our study found various mobile apps that explored virtual reality and augmented reality, which can be the grand climax in an interaction that a user expects from an exhibit, with ample creative possibilities. Beyond these, we identified new interactive modes that enhance users" circulation in the museum, the possibility of a "Virtual Tour 360 Degrees", which uses the same technology as Google Street View within the museum's physical space. So, even before the visit, users can observe each corner of the museum and organize their visit better. Finally, many apps allow users to create their own exhibits with to the option of tagging the contents they most enjoyed.

On certain key points, our analysis in this study can assist museum institutions that have plans for the not-so-distant future in developing a mobile app that is an additional tool for visitors' experience with their exhibits. The study presents an inventory of mobile apps from diverse institutions, and we highlight those that scored the highest on design principles. We also propose a methodology for elaborating a user-centered interaction design that institutions can use to their benefit. It is important to note that the museum should know its visitors before engaging in developing an app. As Rogers [2018] stated, "go beyond the obvious by working with others, communities, people themselves, visitors, and audiences and to learn from each other, to work together, and to be inspired by technology".

Our study's main relevance for the field of science communication was having performed a state-of-the-art survey of mobile apps from science museums and centers on the above-mentioned lists. This allowed us to identify in these mobile apps the most interesting characteristics for an app developed and used by science museums and centers, in addition to generating relevant guidelines. The international mapping presented here provides an overview that can be explored further to better understand the challenges and potential in the use of this technology in the context studied.

Beyond these guidelines, as possible spinoffs of the study, we imagine the possibility of applying different methodologies (other than those in the 38 apps), for example, a study focused on the semiotics of such apps, a follow-up of the apps' maintenance by observing their evolution or extinction, and a more practical study with users from certain social groups (especially with the elderly, since it was the group that refused to participate in the study), to plan for the adherence of new users to the use of the museum's mobile app or some improvement to it. The possibilities are vast, due to the steady rise of smartphones and mobile apps used by society. 
Almeida de Souza, E. H. (2018). ‘Dispositivos móveis em museus: proporcionando novas experiências com o uso de recursos de georreferenciamento'. Human Factors in Design 7 (13), pp. 177-190. https://doi.org/10.5965/2316796307132018177.

ASTC (2021a). About. URL: https: / /www . astc .org/about/ (visited on 13th February 2021).

- (2021b). Find an ASTC member. URL: https://www.astc.org/membership/find-an-astc-member/ (visited on 13th February 2021).

Cuseum (2020). 'How museums are leveraging their mobile apps during COVID-19'. URL: https://cuseum.com/blog/2020/5/1/how-museums-are-lev eraging-their-mobile-apps-during-covid-19.

Exploratorium (2001). Electronic Guidebook Forum. URL: https://www . exploratorium. edu/guidebook/forum/report/HH1 .pdf.

Green, L. (2017). 'Should we make an app?' Spokes 33.

URL: https://www.ecsite.eu/activities-and-services/news-and-publicat ions/digital-spokes/issue-33\#section=section-indepth\%5C\&href=/featu re/depth/should-we-make-app.

Guía de centros y museos de ciencia de América Latina y el Caribe (2015). Rio de Janeiro, Brazil: Museu da Vida/Casa de Oswaldo Cruz/Fiocruz: RedPOP. Montevideo, Uruguay: Unesco.

Hirsh-Pasek, K., Zosh, J. M., Michnick Golinkoff, R., Gray, J. H., Robb, M. B. and Kaufman, J. (2015). 'Putting education in "educational" apps: lessons from the science of learning'. Psychological Science in the Public Interest 16 (1), pp. 3-34. https://doi.org/10.1177/1529100615569721.

Hsi, S. (2002). 'The Electronic Guidebook: a study of user experiences using mobile web content in a museum setting'. In: IEEE International Workshop on Wireless and Mobile Technologies in Education (Vaxjo, Sweden, 30th August 2002), pp. 48-54. https://doi.org/10.1109/WMTE.2002.1039220.

International Council of Museums (2020a). 'Museums and end of lockdown: ensuring the safety of the public and staff'.

URL: https://icom.museum/en/covid-19/resources/museums-and-end-of-lo ckdown-ensuring-the-safety-of-the-public-and-staff-2/.

- (2020b). Museums, museum professionals and COVID-19. URL: https://icom.muse um/wp-content/uploads/2020/05/Report-Museums-and-COVID-19.pdf.

Kruk, M. (2015). 'User interface de aplicações móveis para museus: atenção partilhada'. Master's thesis. Universidade de Lisboa.

URL: http://hdl . handle.net/10451/24074.

Lanir, J., Wecker, A., Yosfan, M. and Eilam, B. (2020). 'Using mobile devices as activity aids in a history museum'. In: $\mathrm{AVI}^{2} \mathrm{CH}$ 2020: Workshop on Advanced Visual Interfaces and Interactions in Cultural Heritage (Island of Ischia, Italy, 29th September 2020). New York, NY, U.S.A.: ACM.

URL: http: //ceur-ws.org/Vol-2687/paper5.pdf.

Norman, D. A. (2002). The design of everyday things. New York, NY, U.S.A.: Basic Books.

Preece, J., Rogers, Y. and Sharp, H. (2002). Interaction design: beyond human-computer interaction. New York, NY, U.S.A.: John Wiley \& Sons.

RedPOP (2021). ¿Qué es la RedPOP?

URL: https://www.redpop.org/qu-es-la-redpop (visited on 13th February 2021). 
Rogers, Y. (2018). 'Keynote: moving beyond the obvious'. In: Conference on Mobile Position Awareness Systems and Solutions (COMPASS) (San Francisco, CA, U.S.A.: Exploratorium, 6th-7th September 2018).

URL: https://www. exploratorium.edu/sites/default/files/pdfs/COMPASS _Conference_Proceedings.pdf.

Sanoff, H. (1968). Techniques of evaluation for designers. Raleigh, NC, U.S.A.: North Carolina State University.

Shah, N. F. M. N. and Ghazali, M. (2018). 'A systematic review on digital technology for enhancing user experience in museums'. In: User Science and Engineering. 5th International Conference, i-USEr 2018 (Puchong, Malaysia, 28th-30th August 2018). Ed. by N. Abdullah, W. A. Wan Adnan and M. Foth. Vol. 886. Communications in Computer and Information Science. Singapore: Springer. https://doi .org/10.1007/978-981-13-1628-9_4.

Spencer, K. (2020). 'Leveraging smartphone technology to protect museum visitors'. American Alliance of Museums. URL: https: //www . aam-us . org/2020/07 /03/leveraging-smartphone-technology-to-protect-museum-visitors/. Valadares Cendón, B. (2001). 'Ferramentas de busca na Web'. Ciência da Informação 30 (1), pp. 39-49. https://doi.org/10.1590/s0100-19652001000100006.

Authors

Maycon Gomes Barbosa is a designer and master in science communication at the Casa de Oswaldo Cruz (COC/Fiocruz). Works with science communication since 2012 at the Escola Politécnica de Saúde Joaquim Venâncio (EPSJV/Fiocruz). His research interests are science communication in interaction design, mobile APP for museums and science centers and public research.

E-mail: maycongb13@yahoo.com.br.

Luiz Antonio de Saboya has a Bachelor's degree in Industrial Design from the School of Industrial Design (Esdi/UERJ) (1979) and Master in Design from ID-IIT (Institute of Design, Illinois Institute of Technology), Chicago (1985). He also has specializations in the areas of Industrial Engineering (1982) and Systems Analysis (1987). In 2016 he completed his doctorate at EBA-UFRJ (School of Fine Arts), Postgraduate Program in Visual Arts, Image and Culture line. He has been a professor at Esdi since 1990, having been Deputy Director there for six years and having served as head of department for some periods. He served as senior technologist at Fiocruz (Fundação Oswaldo Cruz), inside the Museum of Life/Casa de Oswaldo Cruz, since 1996 up to 2019, developing activities related to science communication. From 1989 to 2001 he was assistant professor at Univercidade (Centro Universitário da Cidade). Has experience in the area of Industrial Design, with an emphasis on Product Design, acting mainly on the following themes: design, equipment, science communication, culture and non-formal education. He developed design projects that reached the production line, as well as studies and research in the fields of neonatal and children equipment and civil defense.

E-mail: 1saboya@esdi.uerj.br.

Diego Vaz Bevilaqua, Ph.D., is senior advisor of Science Communication at Casa de Oswaldo Cruz of Fiocruz in Brazil. With formal training in Physics, he has been devoting the last 15 years working with science education and science communication. He served as director of Museu da Vida and currently it is board member of the International Committee for Museums and Collections of Science and Technology (CIMUSET) from ICOM, executive board member of the Brazilian 
Association of Science Centers and Museums (ABCMC) and scientific editor of Ciência Hoje magazine. Diego's research and engagement involves social impact of science communication, art and science and new technologies applied to science communication with emphasis on interactivity. E-mail: diego.bevilaqua@fiocruz.br.

How to cite

Barbosa, M. G., de Saboya, L. A. and Bevilaqua, D. V. (2021). 'A survey and evaluation of mobile apps in science centers and museums'. JCOM 20 (05), A01. https://doi.org/10.22323/2.20050201. 